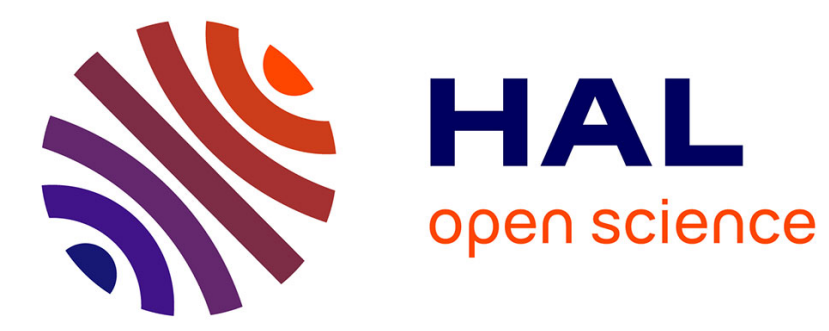

\title{
Rational Engineering of the Dielectric Properties of Thin Silica Layers with a Single Plane of AgNPs
}

Charles Rigoudy, Kremena Makasheva, Mohamed Belhaj, Sarah Dadouch, G. Teyssedre, Laurent Boudou

\section{- To cite this version:}

Charles Rigoudy, Kremena Makasheva, Mohamed Belhaj, Sarah Dadouch, G. Teyssedre, et al.. Rational Engineering of the Dielectric Properties of Thin Silica Layers with a Single Plane of AgNPs. IEEE Internat. Conf. on Dielectrics (ICD), Valencia, Spain, 5-9 July 2020, Jul 2020, Valencia, Spain. pp. 205-208. hal-03003165

\section{HAL Id: hal-03003165 \\ https://hal.science/hal-03003165}

Submitted on 13 Nov 2020

HAL is a multi-disciplinary open access archive for the deposit and dissemination of scientific research documents, whether they are published or not. The documents may come from teaching and research institutions in France or abroad, or from public or private research centers.
L'archive ouverte pluridisciplinaire HAL, est destinée au dépôt et à la diffusion de documents scientifiques de niveau recherche, publiés ou non, émanant des établissements d'enseignement et de recherche français ou étrangers, des laboratoires publics ou privés. 


\title{
Rational Engineering of the Dielectric Properties of Thin Silica Layers with a Single Plane of AgNPs
}

\author{
C. Rigoudy ${ }^{1,2}$, K. Makasheva ${ }^{1}$, M. Belhaj ${ }^{2}$, S. Dadouch ${ }^{2}$, G. Teyssedre ${ }^{1}$, and L. Boudou ${ }^{1}$ \\ ${ }^{1}$ LAPLACE, Université de Toulouse, CNRS, UPS, INPT, 118 route de Narbonne, 31062 Toulouse Cedex 9, France \\ ${ }^{2}$ ONERA - The French Aerospace Lab, 31062 Toulouse Cedex 4, France
}

\begin{abstract}
Interface properties of dielectrics are of outmost importance when dealing with phenomena as charge injection or secondary electron emission. When the dielectric thickness scales down to the $\mathrm{nm}$ range, a deviation from the bulk material properties occurs; therefore, a possibility to tune the surface properties comes by modifying dielectrics at its sub-surface. This paper focuses on the precision of plasma-based processes in order to elaborate thin silica dielectric layers with a single plane of silver nanoparticles (AgNPs) at its sub-surface and thus to control their behavior under electrical stress. An illustration of the modulated properties of such nanostructured dielectrics is given through current measurements and electron emission.
\end{abstract}

\section{INTRODUCTION}

The dielectric charging phenomenon, i.e. the ability of dielectric materials to trap electrical charges, leads to modification of the local electric field. It causes change in the electrical behavior, and on a longer term degradation of the dielectric properties of materials under electrical stress [1,2]. The dielectric charging phenomenon is twofold: $(i)$ it lays down the principle of operation of many applications, among which non-volatile memories [3] and electret based microphones [4], and (ii) it is considered the main cause of electrostatic sticking in MicroElectroMechanical Systems (MEMS) [5], charge build-up and breakdown in insulations $[2,6,7]$ or being at the origin of potential gradients that may generate ElectroStatic Discharges (ESD), thus damage electronic devices and limit their lifetime, especially in space environment [8]. The later example is closely related to another physical phenomenon, namely electron emission from dielectrics under irradiation. In general, the emission efficiency is extremely sensitive to the surface properties of irradiated materials (composition, surface state, etc.), since the secondary electrons are typically emitted from the first $10 \mathrm{~nm}$ beneath the surface of the irradiated material. Main solutions to avoid ESD in those cases are oriented to geometric optimization of the devices and to design of surface coatings.

Even though the required outcome is on macroscopic level the solution is often existing at nanoscale and can be achieved by rational engineering of the dielectric properties of materials [6]. The lately developed nanometric dielectrics, or so-called nanodielectrics, have shown a considerable progress on many of the global electrical parameters of nanocomposite dielectrics (permittivity, losses, low field conductivity, space charge, etc.) since the pioneer works in the early 90s [9]. The Total Electron Emission Yield (TEEY) from dielectric materials under irradiation is one of the global parameters to control, when the featured application is intended for space environment. Therefore, sustainable solution calls for fine tuning of the material composition and structure, and a thorough analysis of the dielectric charging phenomenon.

This work aims to explore the impact of metal inclusions (silver nanoparticles, AgNPs), embedded in thin silica $\left(\mathrm{SiO}_{2}\right)$ layers, on the physical mechanisms responsible for dielectric charging and electron emission, in order to modulate them. Our strategy relies on synthesis of thin stratified coatings and is based on the principle of combined effect from metal/ dielectric interfaces. An illustration of the modified properties of such nanostructured dielectrics is given through current measurements and electron emission in space environment.

Elaboration of stratified dielectric thin films requires facilities/methods permitting strict control of alignment of the metal inclusions at a given nanometric distance beneath the surface. Chemical or physical-based methods, or combination of both, can reply to the above requirements, however with different accuracy. Although well adapted for technological transfer the chemical (wet) methods for synthesis present various drawbacks as wasted materials (solvents), lack of precision in the metal NPs plane depth, uncertainties of the NPs distribution in the plane or different types of ligands that may preferentially trap electrical charges. Combined elaboration methods like dry dipping followed by plasma deposition [10], or physical methods like gas aggregation source [11], ion implantation [12], or plasma-based processes as the one employed in this work $[6,7,13]$, should be privileged because of the accuracy in the process and the lack of uncontrolled chemical species surrounding the metal NPs.

\section{Plasma PRocess FOR SAMPLE Elaboration AND CHARACTERIZATION METHODS}

The targeted structures consisted in a single plane of AgNPs embedded at $10 \mathrm{~nm}$ beneath the surface of $200 \mathrm{~nm}$ thick $\mathrm{SiO}_{2}$ layer deposited on mirror polished stainless still and intrinsic $\mathrm{Si}$-substrates. The searched total thickness of this stratified structure was of $220 \mathrm{~nm}$. The selection of stainless still substrates $(3.3 \mathrm{~cm} \times 3.3 \mathrm{~cm})$ was related to the possibility to ensure good electrical contact on the back side for the charge current and electron emission measurements.

To achieve performance of the dielectric structure, the AgNPs should be well aligned in a plane, small enough so that their surface to volume ratio remains large, well distributed in the plane, with density that ensures charge transport regime far from the electrical percolation limit, however with interparticle distance allowing charge transport through tunneling or trap-assisted processes. 


\section{A. Plasma process and real-time monitoring}

The above defined nanostructured thin dielectric layers have been elaborated in a plasma process successfully combining in the same reactor sputtering of a metallic target (physical vapor deposition - PVD) and plasma polymerization (plasma enhanced chemical vapor deposition - PECVD) $[6,7,13]$.

The plasma was sustained in an argon axially-asymmetric radio-frequency (RF, $f=13.56 \mathrm{MHz}$ ) capacitively-coupled discharge at low pressure $(p=5.3 \mathrm{~Pa})$. The RF-driven top electrode (smaller, $10 \mathrm{~cm}$ in diameter) was placed in front of a bottom electrode (larger, $12 \mathrm{~cm}$ in diameter) with a gap distance of $3.5 \mathrm{~cm}$. The bottom electrode and the walls were grounded. The discharge powered electrode was an Ag-made target to bear the silver sputtering. The axially-asymmetric design of this RF discharge induces a self-bias voltage $V_{d c}$ on the powered electrode, controlling in that way the sputtering. The self-bias voltage is at the origin of the acceleration of argon ions towards the silver target to achieve bombardment. The size and density of the deposited AgNPs were controlled by the injected in the plasma power $P=80 \mathrm{~W}\left(V_{d c}=-950 \mathrm{~V}\right)$ and the sputtering time $\left(t_{s}=5 \mathrm{~s}\right)$ for a given pressure.

The $\mathrm{SiO}_{2}$-base and cover layers were deposited in the same reactor in the plasma sustained by $P=120 \mathrm{~W}\left(V_{d c}=-820 \mathrm{~V}\right)$. Optimal parameters for silica deposits have been identified in a previous work for the very same reactor $[6,13]$. Argon was the vector gas $\left(\mathrm{Ar}_{\text {flow }}=2.8 \mathrm{sccm}\right)$. The precursors used for $\mathrm{SiO}_{2}$ deposition were hexamethyldisiloxane (HMDSO, $\left.\mathrm{C}_{6} \mathrm{H}_{18} \mathrm{Si}_{2} \mathrm{O}\right)$ and $\mathrm{O}_{2}\left(\mathrm{O}_{2 \text { flow }}=1.25 \mathrm{sccm}\right)$. The HMDSO was injected by pulses $\left(t_{o n}=3.1 \mathrm{~s}\right.$ and period $\left.T=5 \mathrm{~s}\right)$ giving an average HMDSO flow of $0.248 \mathrm{sccm}$. The total pressure was of $p=7.9 \mathrm{~Pa}$. The thicknesses of the two silica layers were controlled by the deposition time $\left(t_{d \text {-SiO2-base }}=25 \mathrm{~min}\right.$ and $t_{d \text { - }}$ Sio2-cover $=90 \mathrm{~s}$ ). The use of oxygen has two purposes: to bring oxygen atoms needed for the $\mathrm{SiO}_{2}$-deposition and to ensure plasma combustion of the $\mathrm{C}$-content by creating by-products like $\mathrm{CO}, \mathrm{CO}_{2}, \mathrm{COH}_{2}$ in order to evacuate the carbon atoms originating from the HMDSO decomposition.

The plasma state was monitored at each step of the deposition by measurements of the self-bias voltage and by Optical Emission Spectroscopy (OES) with a Princeton Instrument Acton Advanced Sp 2500A in the range $500-$ $600 \mathrm{~nm}$ with resolution of $0.2 \mathrm{~nm}$.

\section{B. Structural characterization methods}

Structural characterization of the resulting samples has been performed to determine the thickness and composition of the plasma silica matrix as well as to obtain the AgNPs size, shape, density and distribution and the total thickness of the structure.

The thicknesses of $\mathrm{SiO}_{2}$ layers were determined by spectroscopic ellipsometry using a Semilab ellipsometer SE2000 platform in the range $250-850 \mathrm{~nm}$. Bruggeman's model was used to analyze the recorded spectra.

The types of molecular bonds within the silica layers were determined by Fourier Transform InfraRed (FTIR) spectroscopy using a VERTEX70 in transmission mode in the range $400-4000 \mathrm{~cm}^{-1}$ with resolution of $2 \mathrm{~cm}^{-1}$. The transmission mode was achieved due to the transparency of intrinsic Si-substrates in the infrared domain.

Transmission Electron Microscopy (TEM) analysis of the elaborated structures in plane and cross-section views was performed with a JEM $2100 \mathrm{~F}$ microscope operating at $200 \mathrm{kV}$.

\section{Characterization of the electrical behavior of the structures}

The electrical properties of the nanostructured layers have been studied through measurements of the polarization currents under strong electric fields and of the TEEY under electronic radiation conditions.

The study of polarization currents under strong electric fields was performed through a protocol of successive and increasing voltages [14]. Each voltage step lasts for $1000 \mathrm{~s}$ and is followed by a depolarization time at $0 \mathrm{~V}$ during $1000 \mathrm{~s}$. The voltage was applied between the metallic substrate and an upper Au-electrode (150 $\mathrm{nm}$ thick and $1 \mathrm{~cm}$ in diameter).

The TEEY measurement were realized under high vacuum $\left(10^{-6} \mathrm{~Pa}\right)$ in the energy range $0-2000 \mathrm{eV}$, using a $2 \mathrm{keV}$ Kimball electron gun, according to the protocol described in details elsewhere [15].

\section{RESULTS AND DISCUSSION}

\section{A. Importance of plasma stability during sample elaboration}

The plasma stability during deposition was real-time monitored by OES and measurements of the self-bias voltage. The intensity of the emission lines is proportional to the electron density and the electron temperature in the plasma and the self-bias voltage is related to the power absorbed in the plasma. Thus, these two indicators reflect the stability of plasma deposition process and consequently, the precision and quality of the deposited layers. Typically, stabilization of the plasma process was achieved 30 min after plasma ignition.

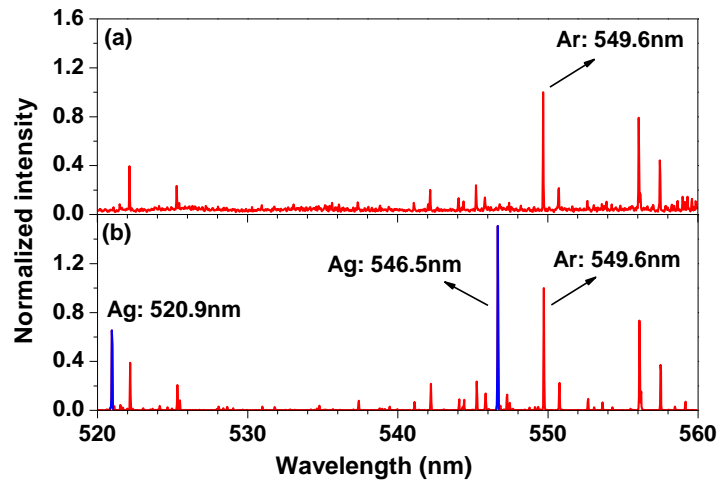

Fig 1. OES spectra recorded during: (a) plasma silica deposition and (b) deposition of the single plane of AgNPs. The spectra are normalized to the intensity of Ar-line at $549.6 \mathrm{~nm}$.

OES spectra of a stable plasma are shown on Fig. 1. For the silica deposition (Fig. 1a) only Ar-lines can be observed in the spectrum. A stable intensity of the Ar-line at $549.6 \mathrm{~nm}$ is a prerequisite to start deposition onto the substrates. Another condition is the absence of Ag-lines. It is achieved when the silver target is completely covered by $\mathrm{SiO}_{2}$ and no Ag-atoms are sputtered into the plasma. For the AgNPs-deposition however, the Ag-lines are clearly observed (Fig. 1b). To 
correlate the amount of sputtered silver we use as indicator the ratio between the intensities of Ag- (at $546.5 \mathrm{~nm}$ ) and $\mathrm{Ar}$ - (at $549.6 \mathrm{~nm})$ lines. The same intensity ratio $\left(\mathrm{I}_{\mathrm{Ag}(546.5 \mathrm{~nm})} / \mathrm{I}_{\mathrm{Ar}(549.6 \mathrm{~nm})}\right)$ is a criterion for reproducibility of the AgNPs-deposition.

Stability of the emission line intensities and of the self-bias voltage are the two key parameters in the deposition process, especially for long deposition times, as they give possibility to associate the deposition time to the composition (in particular the silica layer quality) and the thickness of deposited layers.

B. Quality of the plasma deposited $\mathrm{SiO}_{2}$ layers and quantitative analysis of the single layer of AgNPs

The homogeneity of the $\mathrm{SiO}_{2}$-layer thickness was evaluated by ellipsometry measurements after mapping the entire surface of the stainless still substrates $\left(10.9 \mathrm{~cm}^{2}\right)$. The thickness map gives less than $10 \%$ difference between the thinnest and the thickest point.

According to the above given plasma conditions and deposition times the $\mathrm{SiO}_{2}$ base layer is found $187.1 \mathrm{~nm}$ thick and the thickness of the $\mathrm{SiO}_{2}$ cover layer is $9.1 \mathrm{~nm}$.

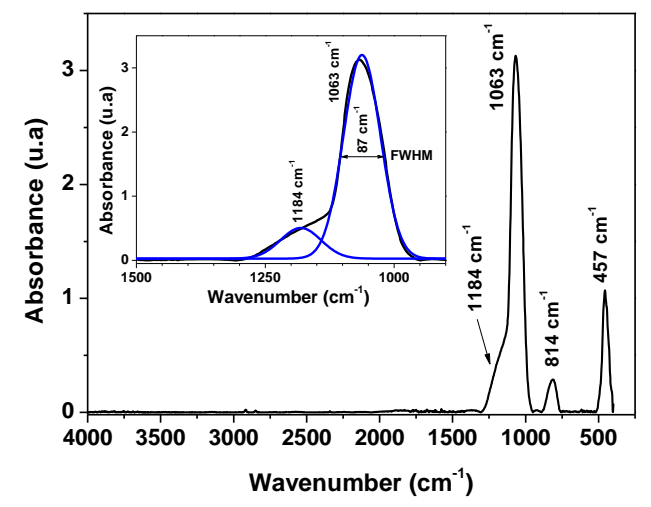

Fig 2. FTIR spectrum for a sample of plasma $\mathrm{SiO}_{2}$. Insert: Deconvolution of the asymmetrical stretching peak and shoulder.

FTIR measurements were performed systematically in order to control the structural properties of the elaborated $\mathrm{SiO}_{2}$ layers. The three characteristic peaks of $\mathrm{Si}-\mathrm{O}-\mathrm{Si}$ vibrations are detected on the FTIR spectrum of $\mathrm{SiO}_{2}$ layers (Fig. 2). Indeed, the rocking at $457 \mathrm{~cm}^{-1}$, the symmetrical stretching at $814 \mathrm{~cm}^{-1}$ and the asymmetrical stretching at $1063 \mathrm{~cm}^{-1}$, including the shoulder at $1184 \mathrm{~cm}^{-1}$ are visible on the spectrum. The plasma silica FTIR spectrum differs from a thermal $\mathrm{SiO}_{2}$ one for the slightly larger full width at half maximum (FWHM) of the asymmetrical stretching: $87 \mathrm{~cm}^{-1}$ for the plasma $\mathrm{SiO}_{2}$ compared to $78 \mathrm{~cm}^{-1}$ for thermal $\mathrm{SiO}_{2}$. Although the used HMDSO precursor contains carbon, no carbon-traces are detectable on the FTIR spectrum. Presence of only $\mathrm{SiO}_{2-}$ associated bonds means that the plasma process conditions and stability are met to grow a dielectric layer with composition and structure very near to that of thermal silica.

TEM imaging allows a direct observation of the elaborated structure (Fig. 3). The total thickness of the structure is measured from the cross section view (Fig. 3a). It is found $206 \mathrm{~nm}$. The base $\mathrm{SiO}_{2}$ layer is of $182 \mathrm{~nm}$ and the $\mathrm{SiO}_{2}$ cover layer is of $9.5 \mathrm{~nm}$. These values confirm the ones found by spectroscopic ellipsometry. Moreover, they are very close to the targeted layer thicknesses $190 \mathrm{~nm}$ and $10 \mathrm{~nm}$, respectively. These results confirm the importance of control during the plasma elaboration, and validate the chosen model to analyze the ellipsometric data. The insert in Fig. 3a shows well that for very thin $\mathrm{SiO}_{2}$ cover layers $(<10 \mathrm{~nm})$ the sample surface topography presents slight waviness reproducing the shape of AgNPs, due to the conformal deposition. Better planarity of the surface is achieved when increasing the depth of the AgNPs plane or when decreasing the size of the nanoparticles.
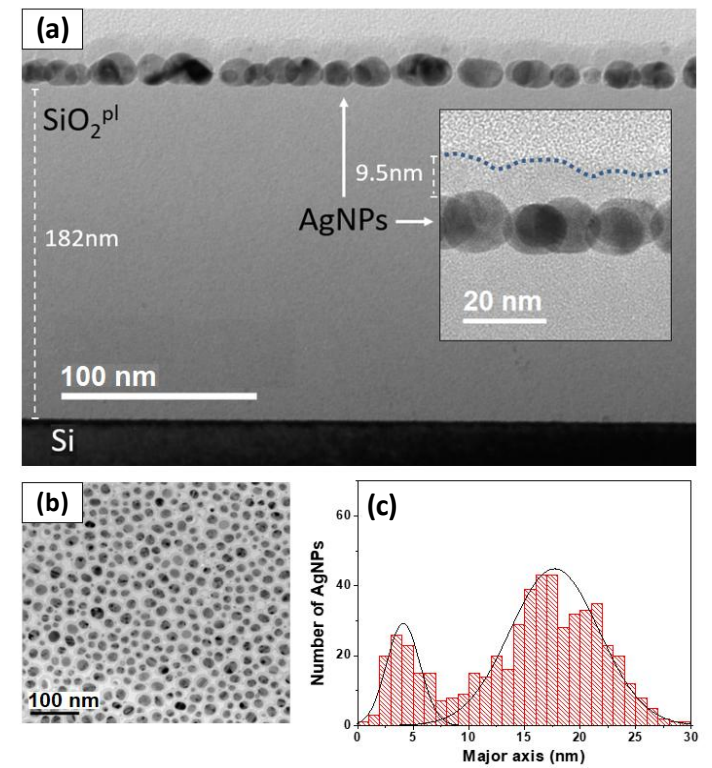

Fig 3. (a) Cross-section view TEM image of the $\mathrm{SiO}_{2} / \mathrm{AgNPs}$ sample. Insert: enlargement of the near surface part. (b) Plane view TEM image of the $\mathrm{SiO}_{2} / \mathrm{AgNPs}$ sample, (c) Statistical distribution of the AgNPs' major axis.

The plane view (Fig. 3b) of the sample shows that the AgNPs are well distributed in the plane and are far from percolation. Statistics on the AgNPs size are shown on Fig. 3c. The AgNP-distribution in size is bimodal with major axis centered at $4.1 \mathrm{~nm}$ and $17.8 \mathrm{~nm}$ for smaller and larger NPs. The AgNPs are of prolate spheroid shape, with eccentricity factor of 0.38 and 0.44 for the small and the large AgNPs respectively, in agreement with previous work [6,13]. Dark Field TEM imaging allowed us to conclude that the AgNPs are polycrystalline. No oxidation of the AgNPs was detected. It means that the $\mathrm{SiO}_{2}$ cover layer protect the AgNPs plane from oxidation, thus their metallic character is preserved.

TEM imaging approves the quality of the plasma elaboration process. This verification is mandatory in order to accurately evaluate the impact of the nanostructuration, i.e. the nanometer scale parameters on the global electrical properties.

\section{Current density under high electric field}

As discussed before the dielectric charging leads to numerous complications over time, over use or under irradiation. Inclusion of AgNPs is a way to modify the electrical properties of a material, however preserving its dielectric behavior. The metallic nature of AgNPs increases the apparent relative permittivity of the nanocomposite. However, the AgNPs can also behave as artificial charge traps, which once occupied generate an internal electric field that 
opposes to the charges injection [7]. Comparison of the current density as a function of the electric field for a $\mathrm{SiO}_{2}$ layer and the presented above nanostructured layer is given in Fig. 4. The precision in the elaboration process allowed us to compare the global response of the $\mathrm{SiO}_{2}$ dielectric layers that differ at nanoscale level. One of the main differences found in conductivity data is that the current density at low field is 4 orders of magnitude higher with AgNPs than without.

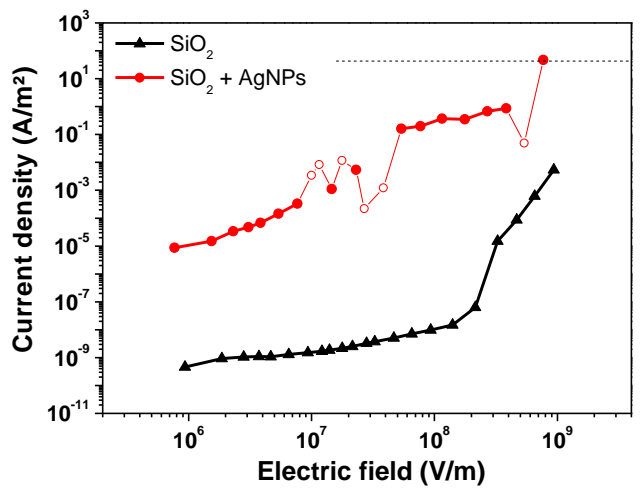

Fig 4. Current density vs. electric field of thin $\mathrm{SiO}_{2}$ layer (black triangle) and the $\mathrm{SiO}_{2} / \mathrm{AgNPs}$ nanostructure (red points). The open red points represent instabilities in the current density measurements.

Present results show that a single plane of AgNPs within a plasma silica matrix deeply impacts the transport, trapping and release of electrical charges, which depends among others on the distance between the AgNPs plane and the sample surface. The influence on the electrical properties of the AgNPs size, and the AgNPs plane depth will be detailed in coming works.

\section{Modifications in the Total Electron Emission Yield}

Under irradiation, the TEEY is globally higher for dielectrics, being around 3 for a bulk $\mathrm{SiO}_{2}$, compared to metals for which it is around 2. Fig. 5 shows the TEEY of the thin $\mathrm{SiO}_{2}$ layer alone and the nanostructured one with embedded at $9.5 \mathrm{~nm} \mathrm{AgNPs.}$

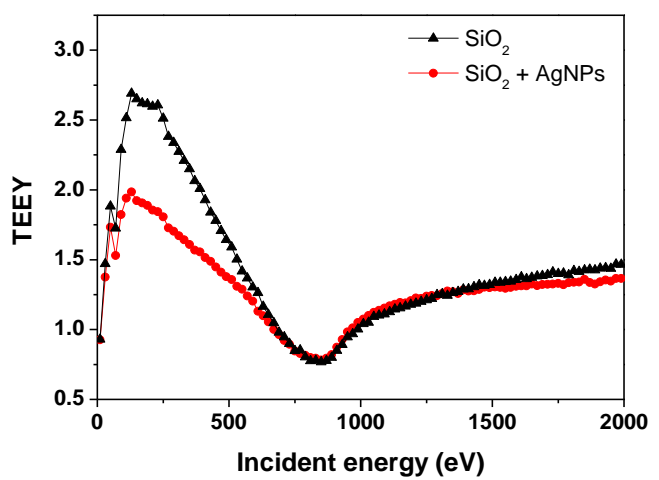

Fig 5. Total Electron Emission Yield of thin $\mathrm{SiO}_{2}$ layers with AgNPs (red points) and without (black triangle).

The atypical shape of the TEEY is due to the small thickness of the dielectric layer [15]. However, one can see that addition of a single plane of AgNPs lowers the TEEY curve toward metal-like sample at low energy (Fig. 5). The global shape remains the same, the specific behavior of the thin dielectric is preserved. With this structure, the lowering can be modulated by varying the size as well as the depth of the AgNPs plane.

\section{CONCLUSION}

In this study we explored the capacity of plasma-based deposition method to elaborate thin nanocomposite dielectric layers consisting of silica matrix with embedded single plane of AgNPs at a controlled distance from the surface. The precise control down to $\mathrm{nm}$ on the dielectric layer thickness, as well as on the dimensions of the AgNPs allows evaluation of the impact of nanoscale structuration on the global electrical properties of thin dielectrics and opens the avenue for rational engineering of the dielectric properties of thin silica layers.

\section{ACKNOWLEDGMENT}

Research supported by the program IDEX Actions Thématiques Stratégiques - ATS 2015 of the Université de Toulouse under project SEPHIR (2016-066-CIF-D-DRVD). The authors acknowledge support from the UMS Raymond Castaing of Université de Toulouse and thank Dr. A. Pugliara and Mr. L. Weingarten for the TEM observations.

\section{REFERENCES}

[1] C. A. Rezende et al., "Detection of charge distributions in insulator surfaces," J. Phys.: Condens. Matter., vol. 21, pp. 263002-263021, 2009.

[2] C. Laurent, G. Teyssedre, S. Le Roy, and F. Baudoin, "Charge dynamics and its energetic features in polymeric materials," IEEE Trans. Dielectr. Electr. Insul., vol. 20, pp. 357-381, 2013.

[3] R. A. Rao et al., "Silicon nanocrystal based memory devices for NVM and DRAM applications," Solid-State Electron., vol. 48, pp. 1463-73, 2004.

[4] G.M. Rebeiz, RF MEMS: Theory, Design, and Technology. Hoboken, NJ, USA: Wiley, 2003.

[5] J. Hillenbrand, S. Haberzettl, and G. M. Sessler, "Electret microphones with stiff diaphragms," J. Acoust. Soc. Am., vol. 134, pp. EL499-505, 2013.

[6] K. Makasheva, C. Villeneuve-Faure, C. Bonafos, C. Laurent, A. Pugliara, B. Despax, L. Boudou and G. Teyssedre "Dielectric Engineering of Nanostructured Layers to Control the Transport of Injected Charges in Thin Dielectrics," IEEE Transaction on Nanotechnology, vol. 15, pp. 839-848, 2016.

[7] L. Milliere, K. Makasheva, C. Laurent, B. Despax, L. Boudou, and G. Teyssedre, "Silver nanoparticles as a key feature of a plasma polymer composite layer in mitigation of charge injection into polyethylene under dc stress," J. Phys. D: Appl. Phys., vol. 49, p. 015304, 2016.

[8] N. Balcon, D. Payan, M. Belhaj, T. Tondu, and V. Inguimbert, "Secondary electron emission on space materials: Evaluation of the total secondary electron yield from surface potential measurements," IEEE Trans. Plasma Sci., vol. 40, pp. 282- 290, 2012.

[9] T. J. Lewis, "Nanometric dielectrics," IEEE Trans. Dielect. Electr. Insul., vol. 1, pp. 812-825, 1994.

[10] X. Deng et al., "Antimicrobial nano-silver non-woven polyethylene terephthalate fabric via an atmospheric pressure plasma deposition process," Sci. Rep., vol. 5, p. 10138, 2015.

[11] T. Peter et al., "High rate deposition system for metalcluster/SiOxCyHz - polymer nanocomposite thin films," J. Nanopart. Res., vol. 15, p. 1710, 2013.

[12] R. Carles, et al., "The synthesis of single layers of Ag nanocrystals by ultra-low-energy ion implantation for largescale plasmonic structures," Nanotechnology, vol. 20, p. 355305, 2009.

[13] A. Pugliara, C. Bonafos, R. Carles, B. Despax, and K. Makasheva, "Controlled elaboration of large-area plasmonic substrates by plasma process," Mater. Res. Exp., vol. 2, p. 065005, 2015.

[14] K. Makasheva, B. Despax, L. Boudou, and G. Teyssedre, "Dielectric layers for RF-MEMS switches: design and study of appropriate structures preventing electrostatic charging," IEEE Trans. Dielec. Electr. Insul., vol. 19, pp. 1195-1202, 2012.

[15] C. Rigoudy, K. Makasheva, G. Teyssedre, M. Belhaj, S. Dadouch and L. Boudou, "Study of required conditions to limit the dielectric charging phenomenon when measuring the electron emission yield from thin dielectric layers," Proc. IEEE Int. Conf. on Dielectr. (ICD), pp. 1-4, 2018. 